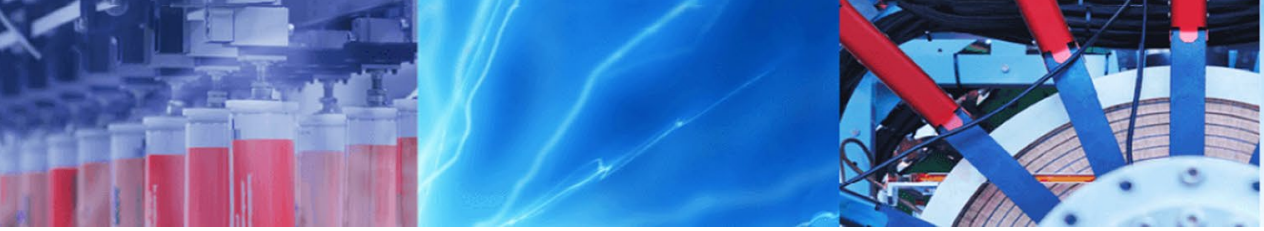

Research Article

\title{
The use of titanium (IV) phosphate for metal removal from aqueous and alcoholic samples
}

\author{
Angelo R. F. Pipi ${ }^{1,2} \cdot$ Sidney Aquino Neto ${ }^{3}$ Priscila Fernanda Pereira Barbosa ${ }^{2}$. Devaney R. Do Carmo ${ }^{2}$
}

() Springer Nature Switzerland AG 2019

\begin{abstract}
Adsorption methods are widely employed for the removal of metals from aqueous medium, being an efficient and environmentally friendly technique for wastewater treatment. From the several adsorptive materials that are being employed by the specialized literature in removal processes, $\mathrm{TiO}_{2}$ continues to be a wise choice. In this work, we have prepared a phosphate-modified $\mathrm{TiO}_{2}(\mathrm{TiPh})$ and tested their adsorptive behavior toward different metallic species. TiPh synthesis was carried out from a titanium (IV) isopropoxide in aqueous phosphoric acid solution. The adsorption of $\mathrm{Co}^{+2}, \mathrm{Cu}^{+2}$, and $\mathrm{Ni}^{+2}$ in a TiPh matrix was investigated in different media: water, $42 \%$ ethanol aqueous solution, and pure ethanol. The kinetic assays results indicated that the adsorption equilibrium occurs after 10-40 $\mathrm{min}$, being higher for alcoholic solutions. The higher capacity values were obtained in the $42 \%$ ethanol aqueous solution, in which $N_{f}$ values of $9.1 \times 10^{-4} \mathrm{~mol} \mathrm{~g}^{-1}$, $5.9 \times 10^{-4} \mathrm{~mol} \mathrm{~g}^{-1}$, and $5.1 \times 10^{-4} \mathrm{~mol} \mathrm{~g}^{-1}$ were obtained for $\mathrm{Cu}^{+2}, \mathrm{Co}^{+2}$, and $\mathrm{Ni}^{+2}$, respectively.
\end{abstract}

Keywords Adsorption · Composite - Titanium phosphate - Metal ions · Langmuir adsorption model

\section{Introduction}

Transferring substances of particular interest from a liquid or gaseous phase to a solid material is a widespread concept that can be quite useful for analytical and environmental purposes [1]. The use of adsorption methodology is especially interesting for the removal of metallic species from aqueous solution once they are very hazardous to the environment [2]. Compared to other methods, adsorption processes show high efficiency with the convenience of easy operation, simplicity of design, and economic viability $[3,4]$. In the past decades, various materials have been proposed for the achievement of efficient metal removal from different samples, focusing on both the treatment of wastewater and their quantification in industrial processes. Clays [5], chitosan [6], zeolites [7], different carbon materials [8], among others, are generally focused by research teams worldwide [3]. Another important material in the context of adsorption processes is the multifunctional titanium oxide $\left(\mathrm{TiO}_{2}\right)$ [9-11].

Titanium oxide is one of the most used amphoteric inorganic material in a wide variety of fields, such as analytical, electrochemistry, catalysis, environmental, and material science. $\mathrm{TiO}_{2}$ can be obtained in many forms, such as sol-gels [12], nanoparticles [13], nanofibers [14], and nanotubes [15]. Thanks to their biocompatibility, stability, and environmental safety, titanium oxide has been applied in different manners such as solar energy conversion devices [16], photocatalysis [17], sensors [18], and photochromic devices [19]. In addition, because of their high ion exchange capacity, another promising aspect of this inorganic material is to act as an inorganic ion exchanger and sorbent, thus being useful for solid-phase extractions [20]. Considering the use of titanium oxide for adsorption

$\triangle$ Devaney R. Do Carmo, devaneydocarmo@hotmail.com | ${ }^{1}$ Pró-Reitoria de Pesquisa e Pós-Graduação (PRPPG), Universidade do Sagrado Coração - USC, Rua Irmã Arminda, 10-50, Bauru, São Paulo CEP 17011-160, Brazil. ${ }^{2}$ Departamento de Física e Química, Faculdade de Engenharia de Ilha Solteira, UNESP - Univ Estadual Paulista, Av. Brasil Centro, 56, Ilha Solteira, SP CEP 15385-000, Brazil. ${ }^{3}$ Departamento de Química, Faculdade de Filosofia Ciências e Letras de Ribeirão Preto, Universidade de São Paulo, Ribeirão Preto, SP 14040-901, Brazil. 
purposes, there are numerous works on the specialized literature, mainly for the removal of dyes and metallic species. In the first situation, dyes can be removed from aqueous solution directly via adsorption as well as by simultaneous adsorption and photocatalysis. Duta and Visa have shown the preparation of a fly-ash- $\mathrm{TiO}_{2}$ composite for the simultaneous removal of two commercial dyes (bemacid red and bemacid blue) via adsorption and photocatalysis [21]. Considering the use of titanium oxide for metal removal, literature has covered a wide range of species. $\mathrm{Yu}$ and co-workers have shown the arsenite removal from aqueous solutions using $\gamma-\mathrm{Fe}_{2} \mathrm{O}_{3}-\mathrm{TiO}_{2}$ magnetic nanoparticles with simultaneous photocatalytic oxidation and adsorption [22]. Nanostructured $\mathrm{TiO}_{2}$ particles are also shown to be quite efficient for the removal of $\mathrm{Cd}$ (II) from wastewater in engineering practices [23]. $\mathrm{TiO}_{2}$ nanotube is another form of the inorganic material that can be quite efficient for metal removal. Besides displaying a large BET surface area, such material can be employed for simultaneous hydrogen production and copper removal from water samples [24]. Another example is the synthesis of a nanocomposite material containing $\mathrm{TiO}_{2} /$ poly(acrylamidestyrene sodium sulfonate) for the removal of radioactive cesium, cobalt and europium ions [25].

Recently, different functionalized mesoporous conjugate nanomaterials were prepared for harmful organic compound adsorption and then used for diverse uses in metal ion removal and detection [26-34].

In previous investigation, we have prepared a titanium (IV) phosphate copper hexacyanoferrate composite from aqueous phosphoric acid and titanium (IV) isopropoxide (TiPh). The obtained hybrid material was fully characterized and displayed electrochemical stability with good reproducibility for the determination of $\mathrm{N}$-acetylcysteine [35]. In this paper, the focus is placed on the synthesis of phosphate-modified $\mathrm{TiO}_{2}$ and their adsorptive behavior toward different metallic species: $\mathrm{Co}^{+2}, \mathrm{Cu}^{+2}$, and $\mathrm{Ni}^{+2}$. The goal was to evaluate the adsorption ability of this material in different media: water, $42 \%$ ethanol aqueous solution, and pure ethanol. Such evaluation is based on the fact that the presence of metals in many alcoholic beverages such as Brazilian Cachaça can be a significant parameter affecting their consumption, conservation, and their exportation [36].

\section{Materials and methods}

\subsection{Chemicals}

Titanium (IV) isopropoxide, phosphoric acid (85\%), copper (II) chloride, cobalt (II) chloride, and nickel (II) chloride were of analytical grade (p.a Merck) and used without further purification. All solutions were prepared with high-purity water from a Millipore Milli-Q system immediately before use.

\subsection{Synthesis of phosphate-modified $\mathrm{TiO}_{2}(\mathrm{TiPh})$}

Synthesis of the proposed adsorbent material was performed as described below. Titanium isopropoxide was employed as the precursor material for binding of the phosphate groups. Thirty-five milliliters of phosphoric acid was transferred to a $100-\mathrm{mL}$ beaker along with $20 \mathrm{~mL}$ titanium (IV) isopropoxide and $10 \mathrm{~mL}$ water. After homogenization, the mixture was allowed to stand in the dark for $24 \mathrm{~h}$. After that period, the formed solid phase was filtered and dried at room temperature for another day. The final powder material, named TiPh, was stored in a low-humidity environment glass recipient before use.

\subsection{Metal adsorption studies using TiPh}

The metal adsorption studies employing the modified titanium oxide were performed using a batchwise technique in thermostatic flasks at $25.0 \pm 0.1^{\circ} \mathrm{C}$. The goal was to evaluate the adsorption ability of this material in different media: water, $42 \%$ ethanol aqueous solution, and pure ethanol. After equilibria, the samples were filtered to remove the adsorbent material followed by titration of each supernatant.

\subsubsection{Determination of adsorption equilibrium time}

In this step, adsorption experiments as a function time were performed using the modified titanium oxide and each metal species proposed in this work $\left(\mathrm{Co}^{+2}, \mathrm{Cu}^{+2}\right.$, and $\mathrm{Ni}^{+2}$ ). The protocol employed consisted of transferring $50 \mathrm{mg}$ of the functionalized material to the thermostatic flasks, followed by addition of $5 \mathrm{~mL}$ aliquots of each metal solution $\left(5.0 \times 10^{-3} \mathrm{~mol} \mathrm{~L}^{-1}\right)$. The final volume in each flask was kept constant at $50 \mathrm{~mL}$. The mixtures were shaken and collected at different intervals of time $(5,10,20,30,40$ and $50 \mathrm{~min}$ ). After filtration, the nonadsorbed metal ions contained in the supernatant were quantified by titration. For determination of $\mathrm{Cu}^{+2}$ and $\mathrm{Ni}^{+2}$ ions, titrations were performed using $1.0 \times 10^{-3} \mathrm{~mol} \mathrm{~L}^{-1}$ ethylenediaminetetraacetic acid (EDTA) solution as titrant at $\mathrm{pH} 10$, which was maintained by an ammonia/ammonium chloride buffer. Murexide (ammonium purpurate) was employed as indicator in both titrations performed. For determination of $\mathrm{Co}^{+2}$ species, the same procedure using EDTA was employed; however, in this case, $1 \%$ hexamethylenetetramine and xylenol orange were employed as indicators. 


\subsubsection{Adsorbent capacity: adsorption curves}

In this study, the same batchwise technique using thermostatic flasks at $25.0 \pm 0.1^{\circ} \mathrm{C}$ was employed. The amount of adsorbent was kept constant at $50 \mathrm{mg}$, and different aliquots $(2.5,5.0,7.5,10,12.5,15,20,25$ and $30 \mathrm{~mL})$ of the metal standard solutions $\left(5 \times 10^{-3} \mathrm{~mol} \mathrm{~L}^{-1}\right)$ were added in each vial, keeping the final volume in $50 \mathrm{~mL}$. The solutions were stirred for the same time period previously described, followed by filtration. The nonadsorbed metal ions contained in the supernatant were quantified by titration through complexometric titrations as described in the previous item.

\section{Results and discussion}

\subsection{Characterization of TipH}

In a previous work [35], we report a complete characterization of TiPh and their use as an electrochemical sensor for the detection of n-acetylcysteine. Herein, we report its potential as an adsorbent composite for some transition metals such as copper $\left(\mathrm{Cu}^{+2}\right)$, cobalt $\left(\mathrm{Co}^{+2}\right)$ and nickel $\left(\mathrm{Ni}^{+2}\right)$ in different media.

\subsection{Adsorption kinetic studies}

Adsorption kinetic studies were carried out through typical adsorption curves, which are here expressed by the number of mol of solute adsorbed per unit of mass of adsorbent $\left(N_{f}, \mathrm{~mol} \mathrm{~g}^{-1}\right)$ as a function of time (minutes). Adsorption kinetic assays were performed by evaluating the time needed for the metal species $\left(\mathrm{Cu}^{+2}, \mathrm{Co}^{+2}\right.$ and $\left.\mathrm{Ni}^{+2}\right)$ to reach equilibrium with the phosphate-modified $\mathrm{TiO}_{2}$ matrix at constant temperature $\left(25^{\circ} \mathrm{C}\right)$. For each metal evaluated, adsorption assays were performed in water, $42 \%$ ethanol aqueous solution, and pure ethanol. Such solutions aim to simulate real alcoholic samples such as alcoholic beverages and vehicle fuels. By varying the adsorption time from 5 to $50 \mathrm{~min}$, we have observed that in aqueous medium the time required to reach the saturation of TiPh with $\mathrm{Cu}^{+2}, \mathrm{Co}^{+2}$ and $\mathrm{Ni}^{+2}$ ions was about 30,10 and $20 \mathrm{~min}$, respectively, as shown in Fig. 1a. We must also mention that after approximately $20 \mathrm{~min}$, a desorption process of $\mathrm{Ni}^{+2}$ species takes place, reaching a maximum around 30 min with a plateau formation after 40-min experiment. Considering the values obtained in a $42 \%$ ethanol aqueous solution, the adsorption times for the $\mathrm{Cu}^{+2}, \mathrm{Co}^{+2}$, and $\mathrm{Ni}^{+2}$ ions were of about 40,20 , and 30 min, respectively (Fig. 1b). For the test performed in a pure ethanol solution, saturation occurs only after $30 \mathrm{~min}$ for all the evaluated metal ions, as shown in Fig. 1c. Overall, the adsorption kinetic studies showed that saturation time varies quite a lot (from 10 to $40 \mathrm{~min}$ ) depending on the metallic specie as well as on the solution in which the experiment was performed. The terminal phosphate groups anchored in the TiPh structure strongly interact with the metal ions contained in the solution through electrostatic interactions, thus making the $\mathrm{TiO}_{2}$ matrix quite efficient binding agent for the metallic cations. It is also noteworthy to mention that in all three evaluated solutions, the amount of solute adsorbed per unit of mass of adsorbent was always higher for $\mathrm{Cu}^{+2}$ species, followed by $\mathrm{Co}^{+2}$ and $\mathrm{Ni}^{+2}$ ions. Such behavior can be understood considering that the maximum adsorption of metallic species is intrinsically related to the $\mathrm{pH}$ of the solution. Literature has shown that $\mathrm{Cu}^{+2}$ ions should adsorb on solid material more easily in lower $\mathrm{pH}$ values, due to their partial hydrolysis that results in the formation of hydrolyzed species, and $\mathrm{Ni}^{+2}$ species should have higher maximum adsorption in alkaline media due to formation of both $[\mathrm{NiOH}]^{+}$and $\mathrm{Ni}(\mathrm{OH})_{2}$ at these $\mathrm{pHs}$ [37]. Another $\mathrm{TiO}_{2}$-based adsorption material has provided similar kinetic behavior [38].

\subsection{TiPh adsorption capacity}

In order to evaluate the adsorption capacity of the modified $\mathrm{TiO}_{2}$ for each metal ion, sorption isotherms were performed and expressed by the $N_{f} / C$ ratio. The maximum amount of adsorbed metal ions $\left(N_{f}^{\mathrm{max}}\right)$, also named specific sorption capacity, is equal to the quantity of metal ions adsorbed when the concentration $(C)$ tends to saturation. As stated in Eq. 1, the $N_{f}$ values are calculated by the difference between the amount of each metallic ion added before equilibrium $\left(N_{b}\right)$ and the amount of each metallic ions contained in the solution not adsorbed after equilibrium $\left(N_{s}\right)$, divided by the adsorbent matrix mass ( $W$ [39]:

$N_{f}=\frac{\left(N_{b}-N_{s}\right)}{W}$

In all the obtained isotherms, we have observed a similar adsorption behavior, where all the evaluated metal ions display low $N_{f}$ and concentration at the beginning of the experiment. As the experiment proceeds, the concentration of the metal ion increases and the $N_{f}$ value becomes independent until active site saturation occurs and $N_{f}$ reaches a constant value. Figure 2 shows representative adsorption isotherms obtained with the TiPh adsorbent matrix for each metal evaluated. Adsorption capacity assays were performed in water, $42 \%$ ethanol aqueous solution, and pure ethanol. Considering the experiments performed in purified water (Fig. 2a), the results obtained with $\mathrm{Cu}^{+2}$ ions indicate a partial saturation of the TiPh active sites with $13 \times 10^{-4} \mathrm{~mol} \mathrm{~L}^{-1}$ that still increase up to 
Fig. 1 Adsorption kinetic assays performed with the metal species $\mathrm{Cu}^{+2}, \mathrm{Co}^{+2}$, and $\mathrm{Ni}^{+2}$ using the TiPh matrix at $25^{\circ} \mathrm{C}$ : a water, $\mathbf{b} 42 \%$ ethanol aqueous solution, $\mathbf{c}$ pure ethanol
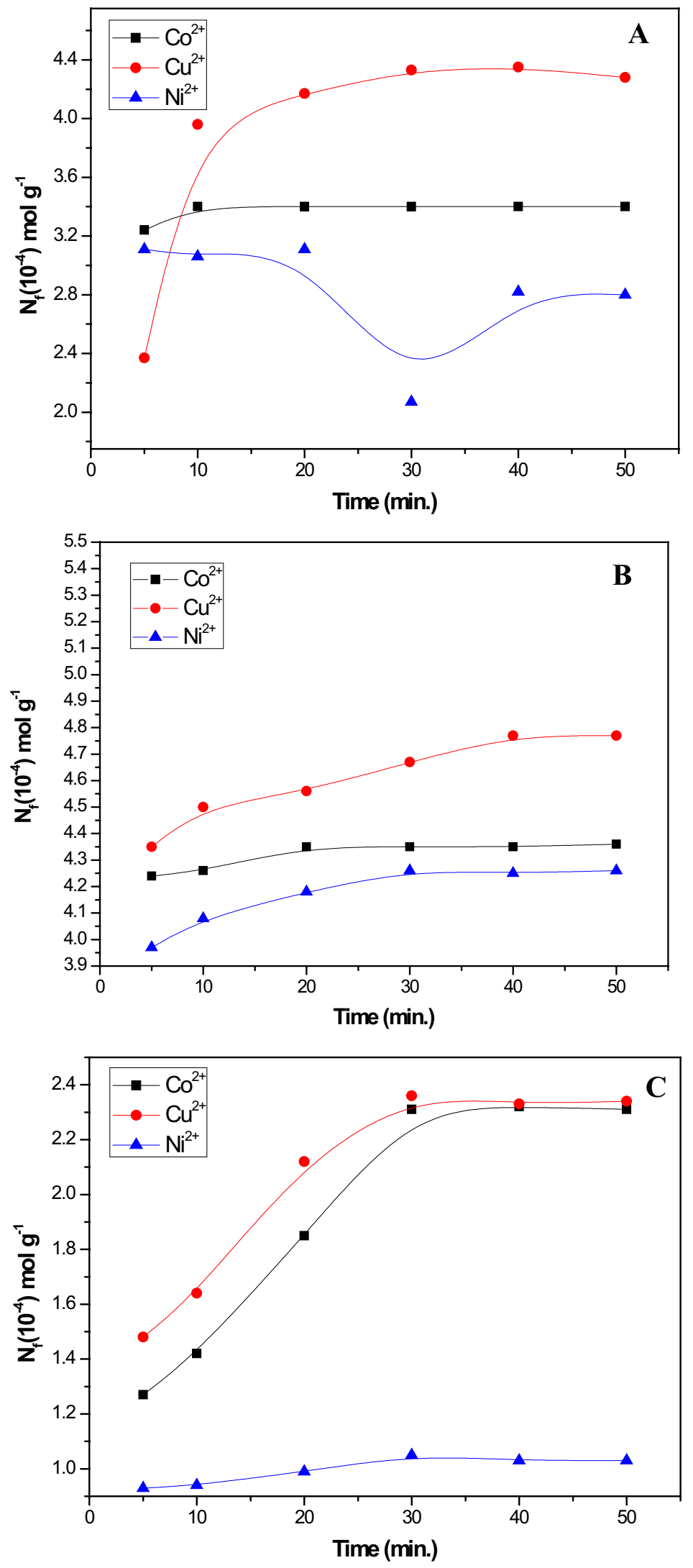

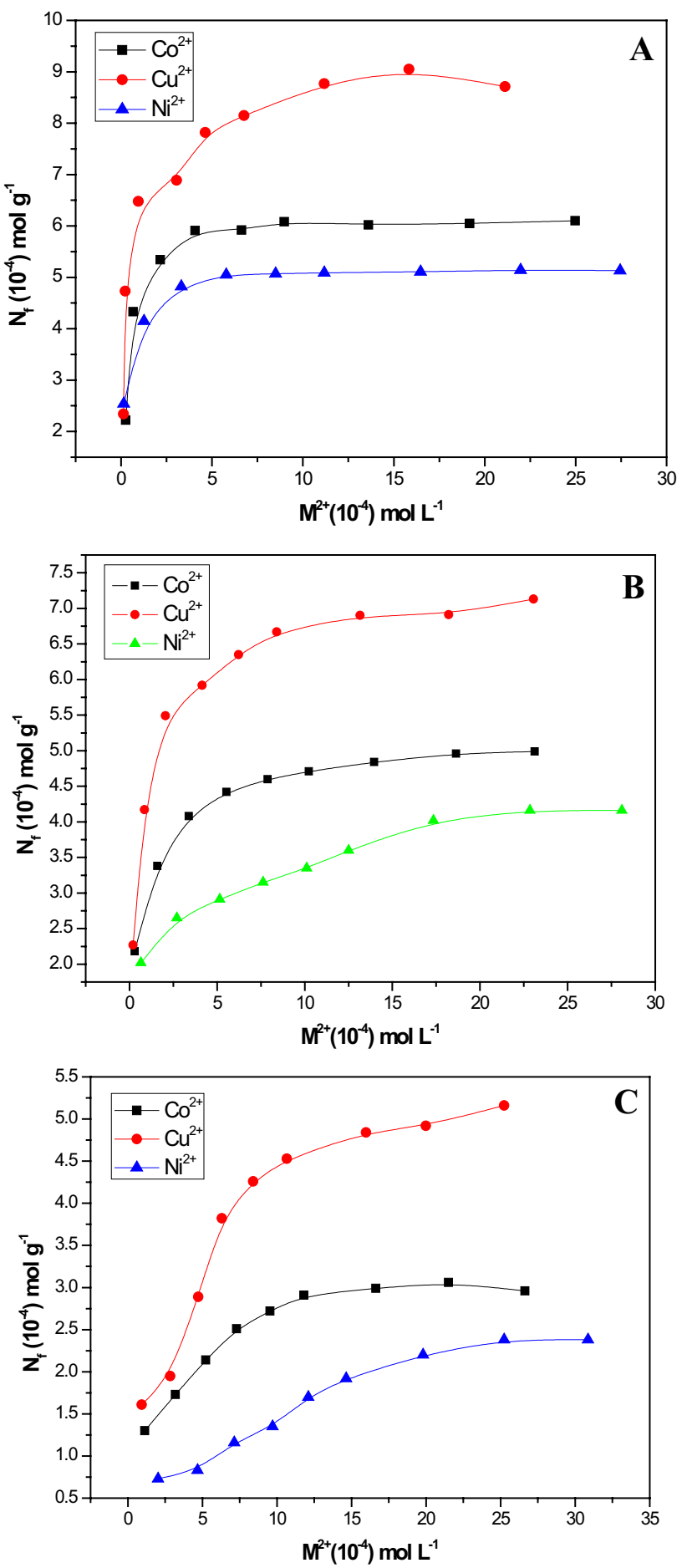

Fig. 2 Adsorption isotherms obtained with the TiPh matrix in different metal ions solutions $\left(\mathrm{Cu}^{+2}, \mathrm{Co}^{+2}\right.$, and $\left.\mathrm{Ni}^{+2}\right)$ at $25^{\circ} \mathrm{C}$ : a water, b $42 \%$ ethanol aqueous solution, $c$ pure ethanol

$23 \times 10^{-4} \mathrm{~mol} \mathrm{~L}^{-1}$, thus leading to an adsorptive capacity of $N_{f}$ of $7.1 \times 10^{-4} \mathrm{~mol} \mathrm{~g}^{-1}$. As for the assay employing the other two metal ions, the isotherms indicate the saturation of TiPh active sites around $18.0 \times 10^{-4} \mathrm{~mol} \mathrm{~L}^{-1}\left(N_{f}\right.$ of $\left.4.97 \times 10^{-4} \mathrm{~mol} \mathrm{~g}^{-1}\right)$ and $22 \times 10^{-4} \mathrm{~mol} \mathrm{~L}^{-1}\left(N_{f}\right.$ of $\left.4.1 \times 10^{-4}\right)$ for $\mathrm{Co}^{+2}$ and $\mathrm{Ni}^{+2}$ ions, respectively. Again, as noticed in the previous section, the adsorption experiments indicate higher adsorption of $\mathrm{Cu}^{+2}$ ions in the TiPh structure, when compared to the other metallic species $\left(\mathrm{Co}^{+2}\right.$ and $\left.\mathrm{Ni}^{+2}\right)$.

The probable adsorption mechanism could be represented by Eq. 2:

$\mathrm{TiPh} \cdot$ solvente $+\mathrm{MX}_{2} \cdot$ solvent $\rightleftarrows \mathrm{TiPh} \cdot \mathrm{MX}_{2} \cdot$ solvent + solvent

where $\mathrm{M}=\mathrm{Cu}^{+2}, \mathrm{Co}^{+2}$, and $\mathrm{Ni}^{+2}$

This matrix is chemically stable and easily reactivated, and does not leach and can be several times reused after percolation of $0.1 \mathrm{~mol} \mathrm{~L}^{-1}$ hydrochloric acid.

Figure $2 \mathrm{~b}$ shows the isotherms obtained in the adsorption capacity experiments performed in a $42 \%$ ethanol aqueous solution containing $\mathrm{Co}^{+2}$, or $\mathrm{Cu}^{+2}$, or $\mathrm{Ni}^{+2}$ ions. Considering the results obtained with $\mathrm{Cu}^{+2}$ ions, we can observe a partial saturation of the TiPh active sites at $11 \times 10^{-4} \mathrm{~mol} \mathrm{~L}^{-1}$, followed by an increase in the adsorptive capacity, reaching values as high as $15 \times 10^{-4} \mathrm{~mol} \mathrm{~L}^{-1}$ with a $N_{f}$ of $9.1 \times 10^{-4} \mathrm{~mol} \mathrm{~g}^{-1}$. For $\mathrm{Co}^{+2}$ species, the obtained isotherm indicates the saturation of TiPh at $4.1 \times 10^{-4} \mathrm{~mol} \mathrm{~L}^{-1}$ with a $N_{f}$ of $5.9 \times 10^{-4} \mathrm{~mol} \mathrm{~g}^{-1}$. As for $\mathrm{Ni}^{+2}$ ions, saturation occurs at $5.8 \times 10^{-4} \mathrm{~mol} \mathrm{~L}^{-1}$ with $\mathrm{N}_{f}$ of $5.1 \times 10^{-4} \mathrm{~mol} \mathrm{~g}^{-1}$. Finally, the adsorptive capacity results registered in pure ethanol are presented in Fig. 2 c. From the obtained $\mathrm{Cu}^{+2}$ isotherm, we could not observe TiPh active sites saturation in the concentration range evaluated. In fact, the maximum $\mathrm{N}_{f}$ recorded in $\mathrm{Cu}^{+2}$ solution was of $5.2 \times 10^{-4} \mathrm{~mol} \mathrm{~g}^{-1}$. Considering the assay performed in a solution containing $\mathrm{Co}^{+2}$ ions, saturation is observed at $16 \times 10^{-4} \mathrm{~mol} \mathrm{~L}^{-1}$ with $N_{f}$ of $3.0 \times 10^{-4} \mathrm{~mol} \mathrm{~g}^{-1}$. In the experiments performed in a pure ethanol solution containing $\mathrm{Ni}^{+2}$ species, TiPh active sites saturation is reached at $25 \times 10^{-4} \mathrm{~mol} \mathrm{~L}^{-1}$ with a $N_{f}$ of $2.4 \times 10^{-4} \mathrm{~mol} \mathrm{~g}^{-1}$.

Additionally, the TiPH is chemically stable and can be reused after 7 months of preparation (+60 cycles), simply by desorbing the metal ion washing the material (TiPHM where $\mathrm{M}=\mathrm{Cu}^{+2}, \mathrm{Ni}^{+2}$ and $\mathrm{Co}^{+2}$ with $\mathrm{HCl} 0.1 \mathrm{M}$ and then with $\mathrm{KOH} 0.1 \mathrm{M}$ to $\mathrm{pH}$ neutral ( 7.0).

Comparing all six isotherms obtained in both alcoholic solutions tested, the absorption values achieved for $\mathrm{Cu}^{+2}$ species remain higher than both $\mathrm{Co}^{+2}$ and $\mathrm{Ni}^{+2}$. Such behavior is justified by the previously mentioned $\mathrm{pH}$ effect, where $\mathrm{Cu}^{+2}$ species should adsorb more easily in TiPh at lower $\mathrm{pH}$ when compared to the other two metals due to the formation of Cu-hydrolyzed species. Higher adsorption values would be achieved for $\mathrm{Ni}$ species, for example, if such experiments were performed in more alkaline regions; however, considering the final goal of this work-preparing a material suitable to be employed for metal quantification and removal in beverage production 
processes-such aspect was not focused on in this work. The adsorption behavior observed in all isotherms is understood considering that removal efficiencies of metal ions are affected by an increase in the ions concentration. At low concentrations, the adsorption process involves the higher energy surface sites, and as the metal species concentration increases, such sites are saturated and adsorption starts to happen on the lower energy surface sites, thus resulting in a decrease in the adsorption efficiency $[40,41]$.

\subsection{Stability studies of the complexes formed on TiPh surface}

The adsorption process of a solute to a solid matrix at constant temperature and volume involves a continuous competition between such species and the solvent molecules that are in contact with the adsorptive material surface. The complete sorption process can be obtained quantitatively from the sorption isotherms, in which the adsorbed amount data are determined after equilibrium. Assuming the formation of monolayers, the Langmuir equation (Eq. 3) can be applied to linearize the sorption isotherms and to estimate important parameters related to equilibrium:

$\frac{C_{s}}{N_{f}}=\frac{C_{s}}{N_{s}}+\frac{1}{N_{s} k}$

In such equation, $C_{s}$ represents the solution concentration at equilibrium (in $\mathrm{mol} \mathrm{L}^{-1}$ ); $N_{f}$ is the adsorbent adsorption capacity (in mol g${ }^{-1}$ ); $N_{s}$ is the maximum amount of solute adsorbed (in $\mathrm{mol} \mathrm{g}^{-1}$ ); and $k$ is the measure of sorption intensity, which is related to the equilibrium constant. The linear regression from the plot of $C_{s} / N_{f}$ as a function of $C_{s}$ gives us $1 / N_{s}$ and $1 /\left(k N_{s}\right)$, which are the slope and the linear coefficients, respectively, allowing us to determine both $k$ and $N_{s}$ values [42]. Figure 3 shows the linearization isotherm plots of $C_{s} / N_{f}$ as a function of $C_{s}$ for each metal ion $\left(\mathrm{Cu}^{+2}, \mathrm{Ni}^{+2}\right.$, and $\left.\mathrm{Co}^{+2}\right)$ evaluated in adsorption assays in water, $42 \%$ ethanol aqueous solution, and pure ethanol.

Table 1 shows all the determined parameters after the adsorption tests employing the TiPh matrix in each solution containing $\mathrm{Cu}^{+2}$, or $\mathrm{Ni}^{+2}$, or $\mathrm{Co}^{+2}$. The $\mathrm{N}_{f}$ maximum values are also presented for comparison purposes.

According to the Langmuir model, $N_{f}$ values approach $N_{s}$ at the surface saturation point. From the data presented in Table 1, we have observed that both $N_{f}$ and $N_{s}$ values determined in all the metallic solutions are quite close to the ones determined for each solvent studied, thus being in agreement with the Langmuir model. In particular, the absorption experiment with $\mathrm{Ni}^{+2}$ ions performed in pure ethanol showed some discrepancy
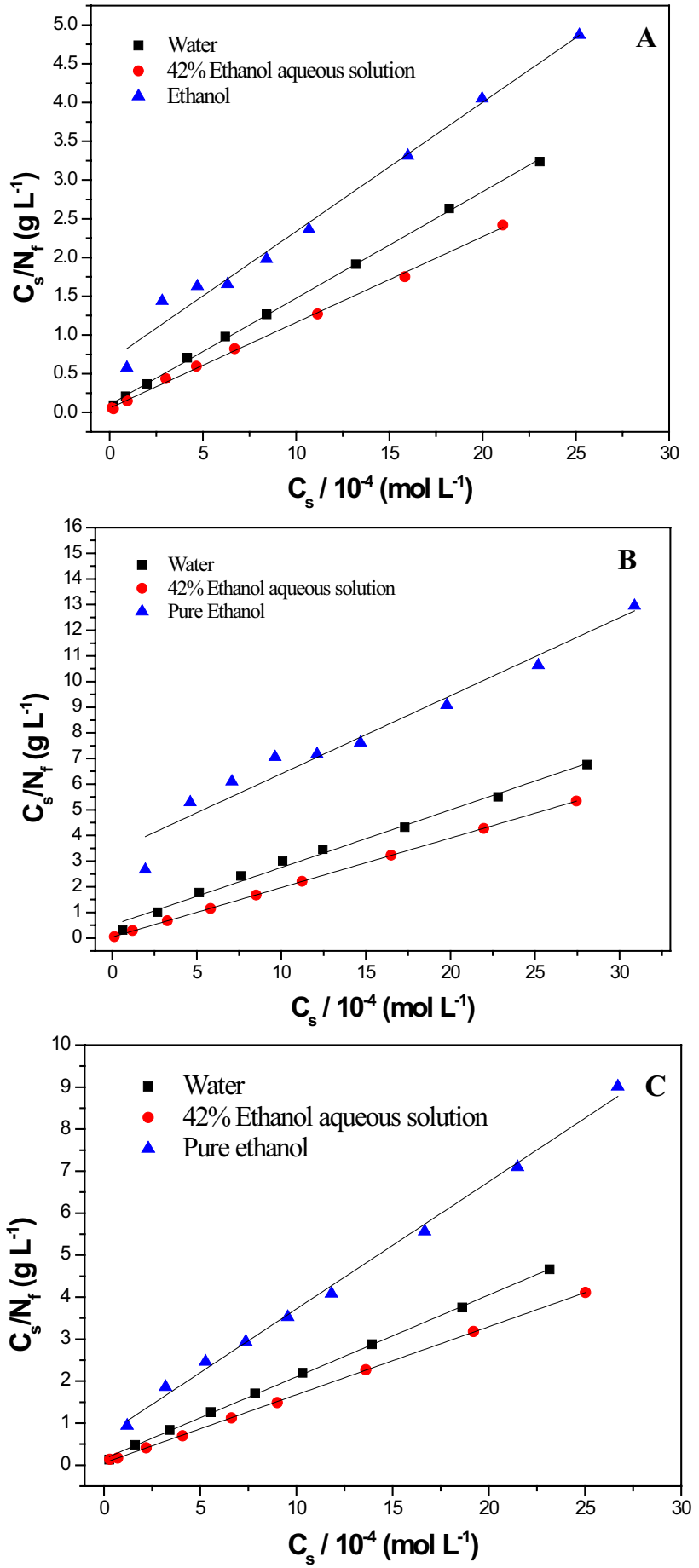

Fig. 3 Linearization isotherms plots of $C_{s} / N_{f}$ as a function of $C_{s}$ for each metal ion evaluated in adsorption assays. $\mathbf{a} \mathrm{Cu}^{+2} . \mathbf{b ~ N i}{ }^{+2}, \mathbf{c}$ $\mathrm{Co}^{+2}$. Adsorption assays were performed in water, $42 \%$ ethanol aqueous solution, and pure ethanol

between the $N_{f}$ and $N_{s}$ values, which is probably related to the low correlation coefficient value obtained in this case or even to possible nonsaturation of the matrix surface in the concentration range studied and evaluated. 
Table $1 k$ and $N_{s}$ values determined by linear regression from the plot of $C_{s} / N_{f}$ as a function of $C_{s}$ after the adsorption assays in water, $42 \%$ ethanol aqueous solution, and pure ethanol with $\mathrm{Cu}^{+2}, \mathrm{Ni}^{+2}$ and $\mathrm{Co}^{+2}$

\begin{tabular}{llllll}
\hline $\begin{array}{l}\text { Metal } \\
\text { adsorbed }\end{array}$ & Solution & $\begin{array}{l}\mathrm{N}_{f}^{\max } 10^{4} \\
\left(\mathrm{~mol} \mathrm{~g}^{-1}\right)\end{array}$ & $\begin{array}{l}\mathrm{N}_{s} 10^{4} \\
\left(\mathrm{~mol} \mathrm{~g}^{-1}\right)\end{array}$ & $\begin{array}{l}k 10^{-3} \\
(\mathrm{~L} \\
\left.\mathrm{mol}^{-1}\right)\end{array}$ & $R$ \\
\hline $\mathrm{Cu}^{+2}$ & Water & 7.1 & 7.3 & 10 & 0.999 \\
& 42\% ethanol & 9.1 & 9.0 & 18 & 0.998 \\
& Pure ethanol & 5.2 & 6.0 & 1.5 & 0.984 \\
$\mathrm{Ni}^{+2}$ & Water & 4.2 & 4.5 & 2.0 & 0.991 \\
& 42\% ethanol & 5.2 & 5.2 & 25 & 0.999 \\
& Pure ethanol & 2.4 & 3.3 & 0.3 & 0.949 \\
$\mathrm{Co}^{+2}$ & Water & 5.0 & 5.1 & 6.6 & 0.999 \\
& 42\% ethanol & 6.1 & 6.2 & 19 & 0.999 \\
& Pure ethanol & 3.0 & 3.3 & 1.5 & 0.995 \\
\hline
\end{tabular}

Table 2 Comparison of adsorption capacity from this modified phosphate with that of different types of sorbents reported in references

\begin{tabular}{llll}
\hline Metal & Adsorbent material & $\begin{array}{l}\text { Adsorption } \\
\text { capacity } \\
\text { (mg/g) }\end{array}$ & References \\
\hline Copper & Biochar & 5.0 & {$[51]$} \\
Copper & Porous ceramsite & 9.42 & {$[52]$} \\
Copper & Pomegranate peel (PGP) & 30.12 & {$[53]$} \\
Copper & PEl-modified mass & 48.60 & {$[54]$} \\
Copper & Modified phosphate & 57.83 & This work \\
Cobalt & DTPA chitosan & 2.35 & {$[55]$} \\
Cobalt & Modified chitosan & 2.78 & {$[56]$} \\
Cobalt & DTPA silica gel & 8.56 & {$[55]$} \\
Cobalt & Palygorskite & 8.88 & {$[57]$} \\
Cobalt & Modified phosphate & 34.76 & This work \\
Nickel & Hybrid membrane & 10.29 & {$[58]$} \\
Nickel & Modified brown algae & 11.67 & {$[59]$} \\
Nickel & Clay adsorbents & 15.70 & {$[60]$} \\
Nickel & Imprinted polymer & 19.86 & {$[61]$} \\
Nickel & Modified phosphate & 29.93 & This work \\
\hline
\end{tabular}

Finally, the isotherms linearization allowed us to calculate the sorption intensity of each complex, represented by the constant $k$. Based on the high values obtained, the complexes formed at the surface of the adsorbent should be thermodynamically stable. In summary, the obtained data are quite satisfactory compared to recent literature displaying a high level of applicability potential [43-50]. For comparison, Table 2 lists the maximum adsorption capacity obtained from this material with that reported in the literature. Clearly, the adsorption capacity of copper(II), cobalt(II) and nickel(II) ions was satisfactory.

\section{Conclusions}

The synthesis of phosphate-modified $\mathrm{TiO}_{2}$ was achieved from their isopropoxide form in an efficient one-pot methodology. The adsorption kinetic assays performed in different solutions containing $\mathrm{Cu}^{+2}, \mathrm{Co}^{+2}$, or $\mathrm{Ni}^{+2}$ indicated that the adsorption equilibrium between the metal species and the TiPh matrix occurs after 10-40 min, being higher in the alcoholic solutions. The amount of metal species adsorbed onto the TiPh surface followed the sequence $\mathrm{Cu}^{+2}>\mathrm{Co}^{+2}>\mathrm{Ni}^{+2}$, which is mainly related to the solution $\mathrm{pH}$ that, once $\mathrm{Cu}^{+2}$ ions should adsorb more easily in the TiPh structure at lower $\mathrm{pH}$ when compared to the other two metals due to the formation of Cu-hydrolyzed species. In the adsorption capacity experiments, the obtained isotherms indicated similar adsorption behavior for all the metal species evaluated, with higher capacity values being achieved in the $42 \%$ ethanol aqueous solution. In such situation, $N_{f}$ values of $9.1 \times 10^{-4} \mathrm{~mol} \mathrm{~g}^{-1}, 5.9 \times 10^{-4} \mathrm{~mol} \mathrm{~g}^{-1}$ and $5.1 \times 10^{-4} \mathrm{~mol} \mathrm{~g}^{-1}$ were obtained for $\mathrm{Cu}^{+2}, \mathrm{Co}^{+2}$ and $\mathrm{Ni}^{+2}$, respectively. Finally, linearization isotherms showed that all the adsorption experiments performed follow the Langmuir model. Moreover, based on the high value of $k$ obtained, the complexes formed at the surface of the adsorbent should be thermodynamically stable. Overall, from all the adsorption experiments in TiPh performed for $\mathrm{Co}^{+2}, \mathrm{Cu}^{+2}$ and $\mathrm{Ni}^{+2}$ in different media, we observed that such material displays high potential applicability for metal quantification and removal, especially for alcoholic solutions such as beverages and vehicle fuels that must have their quantity of metal continuously evaluated during the production process due to the high environmental control that is necessary in such samples.

Acknowledgements Financial support from FAPESP (foundation support research in the state of São Paulo), CAPES (Coordination of Improvement of Higher Level Personnel), and CNPq (National Council for Scientific and Technological Development) is gratefully acknowledged.

\section{Compliance with ethical standards}

Conflict of interest The author(s) declare that they have no competing interests.

\section{References}

1. Dąbrowski A (2001) Adsorption-from theory to practice. Adv Colloid Interface Sci 93:135-224. https://doi.org/10.1016/S0001 -8686(00)00082-8

2. Fu FL, Wang Q (2011) Removal of heavy metal ions from wastewaters: a review. J Environ Manag 92:407-418. https://doi. org/10.1016/j.jenvman.2010.11.011 
3. Babel S, Kurniawan TA (2003) Low-cost adsorbents for heavy metals uptake from contaminated water: a review. J Hazard Mater 97:219-243. https://doi.org/10.1016/S0304 -3894(02)00263-7

4. Bailey SE, Olin TJ, Bricka RM, Adrian DD (1999) A review of potentially low-cost sorbents for heavy metals. Water Res 33:24692479. https://doi.org/10.1016/S0043-1354(98)00475-8

5. Celis R, Hermosin MC, Cornejo J (2000) Heavy metal adsorption by functionalized clays. Environ Sci Technol 34:4593-4599. https ://doi.org/10.1021/es000013c

6. Ngah WSW, Teong LC, Hanafia M (2011) Adsorption of dyes and heavy metal ions by Chitosan composites: a review. Carbohydr Polym 83:1446-1456. https://doi.org/10.1016/j.carbp ol.2010.11.004

7. Motsi T, Rowson NA, Simmons MJH (2009) Adsorption of heavy metals from acid mine drainage by natural zeolite. Int J Miner Process 92:42-48. https://doi.org/10.1016/j.minpro.2009.02.005

8. Kobya M, Demirbas E, Senturk E, Ince M (2005) Adsorption of heavy metal ions from aqueous solutions by activated carbon prepared from apricot stone. Biores Technol 96:1518-1521. https://doi.org/10.1016/j.biortech.2004.12.005

9. Kitano M, Matsuoka M, Ueshima M, Anpo M (2007) Recent developments in titanium oxide-based photocatalysts. Appl Catal A 325:1-14. https://doi.org/10.1016/j.apcata.2007.03.013

10. Sekino T (2010) Synthesis and applications of titanium oxide nanotubes, in inorganic and metallic nanotubular materials: recent technologies and applications. Springer, Berlin

11. Rahimi N, Pax RA, Gray EM (2016) Review of functional titanium oxides. I: $\mathrm{TiO}_{2}$ and its modifications. Prog Solid State Chem 44:86-105. https://doi.org/10.1016/j.progsolidstchem .2016.07.002

12. Wang XD, Shi F, Gao X, Fan C, Huang W, Feng X (2013) A sol-gel dip/spin coating method to prepare titanium oxide films. Thin Solid Films 548:34-39. https://doi.org/10.1016/j.tsf.2013.08.056

13. El-Deen S, Zhang FS (2016) Immobilisation of $\mathrm{TiO}_{2}$-nanoparticles on sewage sludge and their adsorption for cadmium removal from aqueous solutions. J Exp Nanosci 11:239-258. https://doi. org/10.1080/17458080.2015.1047419

14. Chen DZ, Liu C, Chen S, Shen W, Luo X, Guo L (2016) Controlled synthesis of recyclable, porous $\mathrm{FMO} / \mathrm{C} @ \mathrm{TiO}_{2}$ core-shell nanofibers with high adsorption and photocatalysis properties for the efficient treatment of dye wastewater. ChemPlusChem 81:282. https://doi.org/10.1002/cplu.201500534

15. Liu W, Ni JR, Yin XC (2014) Synergy of photocatalysis and adsorption for simultaneous removal of $\mathrm{Cr}(\mathrm{VI})$ and $\mathrm{Cr}(\mathrm{III})$ with $\mathrm{TiO}_{2}$ and titanate nanotubes. Water Res 53:12-25

16. Hochbaum Al, Yang PD (2010) Semiconductor nanowires for energy conversion. Chem Rev 110:527-546. https://doi. org/10.1021/cr900075v

17. Nakata $\mathrm{K}$, Fujishima $\mathrm{A}$ (2012) $\mathrm{TiO}_{2}$ photocatalysis: design and applications. J Photochem Photobiol C 13:169-189. https://doi. org/10.1016/j.jphotochemrev.2012.06.001

18. Li XG, Li X, Wang J, Lin S (2015) Highly sensitive and selective room-temperature formaldehyde sensors using hollow $\mathrm{TiO}_{2}$ microspheres. Sens Actuators B Chem 219:158-163. https:// doi.org/10.1016/j.snb.2015.05.031

19. Djaoued Y, Balaji S, Beaudoin N (2013) Sol-gel synthesis of mesoporous $\mathrm{WO}_{3}-\mathrm{TiO}_{2}$ composite thin films for photochromic devices. J Sol Gel Sci Technol 65:374-383. https://doi. org/10.1007/s10971-013-3218-z

20. Shen Q, Yang M, Li L, Cheung HY (2014) Graphene/TiO 2 nanocomposite based solid-phase extraction and matrix-assisted laser desorption/ionization time-of-flight mass spectrometry for lipidomic profiling of avocado (Persea americana Mill.). Anal Chim Acta 852:153-161. https://doi.org/10.1016/j. aca.2014.09.022
21. Duta A, Visa M (2015) Simultaneous removal of two industrial dyes by adsorption and photocatalysis on a fly-ash- $\mathrm{TiO}_{2}$ composite. J Photochem Photobiol A 306:21-30. https://doi. org/10.1016/j.jphotochem.2015.03.007

22. Yu L, Peng X, Ni F, Li J, Wang D, Luan Z (2013) Arsenite removal from aqueous solutions by $\gamma-\mathrm{Fe}_{2} \mathrm{O}_{3}-\mathrm{TiO}_{2}$ magnetic nanoparticles through simultaneous photocatalytic oxidation and adsorption. J Hazard Mater 246-247:10-17. https://doi.org/10.1016/j.jhazm at.2012.12.007

23. Zha R, Nadimicherla R, Guo X (2014) Cadmium removal in waste water by nanostructured $\mathrm{TiO}_{2}$ particles. J Mater Chem A 2:13932-13941. https://doi.org/10.1039/C4TA02106A

24. Xu S, Ng J, Du AJ, Liu J, Sun DD (2011) Highly efficient $\mathrm{TiO}_{2}$ nanotube photocatalyst for simultaneous hydrogen production and copper removal from water. Int J Hydrogen Energy 36:65386548. https://doi.org/10.1155/2012/843042

25. Borai EH, Breky MME, Sayed MS, Abo-Aly MM (2015) Synthesis, characterization and application of titanium oxide nanocomposites for removal of radioactive cesium, cobalt and europium ions. J Colloid Interface Sci 450:17-25. https://doi.org/10.1016/j. jcis.2015.02.0620021-9797

26. Awual MdR, Miyazaki Y, Taguchi T, Shiwaku H, Yaita T (2016) Encapsulation of cesium from contaminated water with highly selective facial organic-inorganic mesoporous hybrid adsorbent. Chem Eng J 291:128-137. https://doi.org/10.1016/j. cej.2016.01.109

27. Awual MdR (2016) Solid phase sensitive palladium(II) ions detection and recovery using ligand based efficient conjugate nanomaterials. Chem Eng J 300:264-272. https://doi.org/10.1016/j. cej.2016.04.071

28. Awual MR, Hasan MM, Khaleque MA, Sheikh MC (2016) Treatment of copper(II) containing wastewater by a newly developed ligand based facial conjugate materials. Chem Eng J 288:368376. https://doi.org/10.1016/j.cej.2015.11.108

29. Shahat A, Awual MdR, Naushad Mu (2015) Functional ligand anchored nanomaterial based facial adsorbent for cobalt(II) detection and removal from water samples. Chem Eng J 271:155-163. https://doi.org/10.1016/j.cej.2015.02.097

30. Awual MdR, Alharthi N, Hasan MdM, Karim MR, Islam A, Znad $\mathrm{H}$, Hossain MA, Halim MdE, Rahman MM, Khaleque MA (2017) Inorganic-organic based novel nano-conjugate material for effective cobalt(II) ions capturing from wastewater. Chem Eng J 324:130-139. https://doi.org/10.1016/j.cej.2017.05.026

31. Awual MR, Alharthi NH, Okamoto Y, Karim MR, Halim MdE, Hasan MdM, Rahman MM, Islam MM, Khaleque MA, Sheikh MC (2017) Ligand field effect for Dysprosium(III) and Lutetium(III) adsorption and EXAFS coordination with novel composite nanomaterials. Chem Eng J 320:427-435. https://doi.org/10.1016/j. cej.2017.03.075

32. Awual MR, Hasan MM, Eldesoky G, Khaleque MA, Rahman MM, Naushad M (2016) Facile mercury detection and removal from aqueous media involving ligand impregnated conjugate nanomaterials. Chem Eng J 290:243-251. https://doi.org/10.1016/j. cej.2016.01.038

33. Awual MR, Hasan MM, Shahat A, Naushad M, Shiwaku H, Yaita $T$ (2015) Investigation of ligand immobilized nano-composite adsorbent for efficient cerium(III) detection and recovery. Chem Eng J 265:210-218. https://doi.org/10.1016/j.cej.2014.12.052

34. Awuala MdR, Yaita T, Taguchi T, Shiwaku H, Suzuki S, Okamoto Y (2014) Selective cesium removal from radioactive liquid waste by crownether immobilized new class conjugate adsorbent. J Hazard Mater 278:227-235. https://doi.org/10.1016/j.jhazm at.2014.06.01135

35. Pipi ARF, do Carmo DR (2011) Voltammetric studies of titanium (IV) phosphate modified with copper hexacyanoferrate and electroanalytical determination of $\mathrm{N}$-acetylcysteine. J 
Appl Electrochem 41:787-793. https://doi.org/10.1007/s1080 0-011-0296-x

36. Ibanez JG, Carreon-Alvarez A, Barcena-Soto M, Casillas N (2008) Metals in alcoholic beverages: a review of sources, effects, concentrations, removal, speciation, and analysis. J Food Compos Anal 21:672-683. https://doi.org/10.1016/j.jfca.2008.06.005

37. Kadirvelu K, Faur-Brasquet C, Cloirec PL (2000) Removal of Cu(II), $\mathrm{Pb}(\mathrm{II})$, and $\mathrm{Ni}(\mathrm{II})$ by adsorption onto activated carbon cloths. Langmuir 16:8404-8409. https://doi.org/10.1021/la0004810

38. Engates KE, Shipley HJ (2011) Adsorption of Pb, Cd, Cu, Zn, and $\mathrm{Ni}$ to titanium dioxide nanoparticles: effect of particle size, solid concentration, and exhaustion. Environ Sci Pollut Res 18:386395. https://doi.org/10.1007/s11356-010-0382-3

39. Dias Filho NL (1998) Adsorption of copper(II) and cobalt(II) complexes on a silica gel surface chemically modified with 3-amino-1,2,4-triazole. Colloids Surf A Physicochem Eng Asp 144:219-227. https://doi.org/10.1016/S0927-7757(98)00569-X

40. Mark RM, Brian ER (1993) Modeling Cd adsorption in single and binary adsorbent (PAC) systems. J Environ Eng 119:332-348. https://doi.org/10.1061/(ASCE)0733-9372

41. Marzal P, Seco A, Gabaldón C, Ferrer J (1996) Cadmium and zinc adsorption onto activated carbon: influence of temperature, $\mathrm{pH}$ and metal/carbon ratio. J Chem Technol Biotechnol 66:279-285. https://doi.org/10.1002/(SICI) 1097-4660

42. Rosa AH, Goveia D, Bellin IC, Lessa SS, Filho NLD (2006) New analytical procedure based on a cellulose bag and ionic exchanger with $\mathrm{p}$-aminobenzoic acid groups for differentiation of labile and inert metal species in aquatic systems. Anal Bioanal Chem $386: 2153-2160$

43. Awual MdR (2019) Novel conjugated hybrid material for efficient lead(II) capturing from contaminated wastewater. Mater Sci Eng C 101:686-695. https://doi.org/10.1016/j.msec.2019.04.015

44. Awual MdR (2019) Innovative composite material for efficient and highly selective $\mathrm{Pb}$ (II) ion capturing from wastewater. J Mol Liq 284:502-510. https://doi.org/10.1016/j.molliq.2019.03.157

45. Awual MdR, Yaita T, Suzuki S, Shiwaku H (2015) Ultimate selenium(IV) monitoring and removal from water using a new class of organic ligand based composite adsorbent. J Hazard Mater 291:111-119. https://doi.org/10.1016/j.jhazm at.2015.02.066

46. Awuala MdR, Hasanb MdM (2015) Colorimetric detection and removal of copper(II) ions from wastewater samples using tailormade composite adsorbent. J Sens Actuators B 206:692-700. https://doi.org/10.1016/j.snb.2014.09.086

47. Awual MdR, Yaita T, Shiwaku H (2013) Design a novel optical adsorbent for simultaneous ultra-trace cerium(III) detection, sorption and recovery. Chem Eng J 228:327-333. https://doi. org/10.1016/j.cej.2013.05.010

48. Awual MdR, Hasan MdM, Znad H (2015) Organic-inorganic based nano-conjugate adsorbent for selective palladium(II) detection, separation and recovery. Chem Eng J 259:611-619. https://doi.org/10.1016/j.cej.2014.08.028

49. Awual MdR, Yaita T, Shiwaku H, Suzuki S (2015) A sensitive ligand embedded nano-conjugate adsorbent for effective cobalt(II) ions capturing from contaminated water. Chem Eng J 276:1-10. https://doi.org/10.1016/j.cej.2015.04.058
50. Awual MdR, Asiri AM, Rahman MM, Alharthic N (2019) Assessment of enhanced nitrite removal and monitoring using Ligand modified stable conjugate materials. Chem Eng J 363:64-72. https://doi.org/10.1016/j.cej.2019.01.125

51. Hoslett J, Ghazal H, Ahmad D, Jouhara H (2019) Removal of copper ions from aqueous solution using low temperature biochar derived from the pyrolysis of municipal solid waste. Sci Total Environ 673:777-789. https://doi.org/10.1016/j.scito tenv.2019.04.085

52. Qing-xiu J, Yun-yan W, Li-yuan C, Chong-jian T, Xiao-dong H, Huan G, Wei W, Wei Y (2018) Adsorption of copper ions on porous ceramsite prepared by diatomite and tungsten residue. T Nonferrous Met Soc 28:1053-1060. https://doi.org/10.1016/ S1003-6326(18)64731-4.53

53. Ben-Ali S, Jaouali I, Souissi-Najar S, Ouederni A (2017) Characterization and adsorption capacity of raw pomegranate peel biosorbent for copper removal. J Clean Prod 142:3809-3821. https://doi.org/10.1016/j.jclepro.2016.10.081

54. Jiajia D, Yangyang D, Rusheng D, Yu S, Shusheng Z, Runping H (2019) Adsorption of copper ion from solution by polyethylenimine modified wheat straw. Bioresour Technol Rep 6:96-102. https://doi.org/10.1016/j.biteb.2019.02.011

55. Repo E, Malinen L, Koivula R, Harjula R, Sillanpää M (2011) Capture of $\mathrm{Co}$ (II) from its aqueous EDTA-chelate by DTPA-modified silica gel and chitosan. J Hazard Mater 187:122-132. https://doi. org/10.1016/j.jhazmat.2010.12.113

56. Zhuang S, Yin Y, Wang J (2018) Removal of cobalt ions from aqueous solution using chitosan grafted with maleic acid by gamma radiation. Nuclear Eng Technol 50:211-215. https://doi. org/10.1016/j.net.2017.11.007

57. He M, Zhu Y, Yang Y, Han B, Zhang Y (2011) Adsorption of cobalt(II) ions from aqueous solutions by palygorskite. Appl Clay Sci 54:292-296. https://doi.org/10.1016/j.clay.2011.09.013

58. Irani M, Keshtkar AR, Mousavian MA (2011) Removal of Cd(II) and $\mathrm{Ni}$ (II) from aqueous solution by PVA/TEOS/TMPTMS hybrid membrane. Chem Engin J 175:251-259. https://doi. org/10.1016/j.cej.2011.09.102

59. Mehdi M, Rahmati M, Rabbani P, Abdolali A, Keshtkar AR (2011) Kinetics and equilibrium studies on biosorption of cadmium, lead, and nickel ions from aqueous solutions by intact and chemically modified brown algae. J Hazard Mater 185:401-407. https://doi.org/10.1016/j.jhazmat.2010.09.047

60. Gupta SS, Bhattacharyya KG (2006) Adsorption of Ni(II) on clays. J Colloid Interface Sci 295:21-32. https://doi.org/10.1016/j. jcis.2005.07.073

61. He J, Shang H, Zhang X, Sun X (2018) Synthesis and application of ion imprinting polymer coated magnetic multi-walled carbon nanotubes for selective adsorption of nickel ion. Appl Surf Sci 428:110-117. https://doi.org/10.1016/j.apsusc.2017.09.123

Publisher's Note Springer Nature remains neutral with regard to jurisdictional claims in published maps and institutional affiliations. 